\title{
Early and 1-year outcomes of aortic root surgery in patients with Marfan syndrome: A prospective, multicenter, comparative study
}

\author{
Joseph S. Coselli, MD, ${ }^{a}$ Irina V. Volguina, PhD, ${ }^{a}$ Scott A. LeMaire, MD, ${ }^{a}$ Thoralf M. Sundt, MD, \\ Heidi M. Connolly, MD, ${ }^{\mathrm{c}}$ Elizabeth H. Stephens, MD, PhD, ${ }^{\mathrm{d}}$ Hartzell V. Schaff, MD, ${ }^{\mathrm{e}}$ \\ Dianna M. Milewicz, MD, PhD, ${ }^{\mathrm{f}}$ Luca A. Vricella, MD, ${ }^{\mathrm{g}}$ Harry C. Dietz, MD, ${ }^{\mathrm{h}}$ \\ Charles G. Minard, $\mathrm{PhD},{ }^{\mathrm{i}}$ and D. Craig Miller, MD, ${ }^{\mathrm{d}}$ on behalf of the Aortic Valve Operative \\ Outcomes in Marfan Patients Study Group
}

Objective: To compare the 1-year results after aortic valve-sparing (AVS) or valve-replacing (AVR) aortic root replacement from a prospective, international registry of 316 patients with Marfan syndrome (MFS).

Methods: Patients underwent AVS $(n=239,76 \%)$ or AVR $(n=77,24 \%)$ aortic root replacement at 19 participating centers from 2005 to 2010 . One-year follow-up data were complete for 312 patients (99\%), with imaging findings available for 293 (94\%). The time-to-events were compared between groups using Kaplan-Meier curves and Cox proportional hazards models.

Results: Two patients $(0.6 \%)-1$ in each group — died within 30 days. No significant differences were found in early major adverse valve-related events (MAVRE; $P=.6$ ). Two AVS patients required early reoperation for coronary artery complications. The 1-year survival rates were similar in the AVR (97\%) and AVS (98\%) groups; the procedure type was not significantly associated with any valve-related events. At 1 year and beyond, aortic regurgitation of at least moderate severity $(\geq 2+)$ was present in 16 patients in the AVS group (7\%) but in no patients in the AVR group $(P=.02)$. One AVS patient required late AVR.

Conclusions: AVS aortic root replacement was not associated with greater 30-day mortality or morbidity rates than AVR root replacement. At 1 year, no differences were found in survival, valve-related morbidity, or MAVRE between the AVS and AVR groups. Of concern, $7 \%$ of AVS patients developed grade $\geq 2+$ aortic regurgitation, emphasizing the importance of 5 to 10 years of follow-up to learn the long-term durability of AVS versus AVR root replacement in patients with MFS. (J Thorac Cardiovasc Surg 2014;147:1758-67)

Supplemental material is available online.

Earn CME credits at

http://jtcvs.com/cme/home
From the Division of Cardiothoracic Surgery, ${ }^{a}$ Michael E. DeBakey Department of Surgery, Baylor College of Medicine, and Department of Cardiovascular Surgery, Texas Heart Institute, Houston, Tex; Division of Cardiac Surgery, ${ }^{\mathrm{b}}$ Department of Surgery, Massachusetts General Hospital, Boston, Mass; Division of Cardiovascular Diseases, ${ }^{c}$ Mayo Clinic, Rochester, Minn; Department of Cardiothoracic Surgery, ${ }^{\mathrm{d}}$ Stanford University School of Medicine, Stanford, Calif; Division of Cardiovascular Surgery, ${ }^{e}$ Department of Surgery, Mayo Clinic, Rochester, Minn; Division of Medical Genetics, ${ }^{\mathrm{f}}$ Department of Internal Medicine, University of Texas Health Science Center at Houston, Houston, Tex; Division of Cardiac Surgery, ${ }^{\mathrm{g}}$ Department of Surgery, Johns Hopkins Hospital, Baltimore, Md; McKusick-Nathans Institute of Genetic Medicine and Department of Pediatrics, ${ }^{\text {h }}$ Johns Hopkins University School of Medicine and Howard Hughes Medical Institute, Baltimore, Md; and Dan L. Duncan Institute for Clinical and Translational Research, ${ }^{\mathrm{i}}$ Baylor College of Medicine, Houston, Tex.

The present study was sponsored by the National Marfan Foundation and Michael E. DeBakey Department of Surgery, Baylor College of Medicine, Houston, Tex. The National Marfan Foundation received unrestricted support from Vascutek Ltd, St Jude Medical, Inc, and the Macquet Cardiovascular/Getinge Group. Dr Minard is supported by the Dan L. Duncan Institute for Clinical and Translational Research, Baylor College of Medicine, Houston, Tex.
In patients with Marfan syndrome (MFS), cardiovascular complications have been the leading cause of mortality and morbidity, including dilatation and dissection of the aortic root and other segments of the thoracic aorta. If untreated, such complications can lead to life-threatening conditions, including aortic valve regurgitation, congestive heart failure, and aortic rupture. ${ }^{1}$ The underlying cause of aortic disease involves impaired synthesis, secretion, and deposition of

Disclosures: J.S.C. reports consulting fees from Medtronic and Vascutek, lecture fees from St. Jude Medical and Medtronic, and grant support from Medtronic. S.A.L. reports consulting fees for Medtronic. T.M.S. reports consulting fees for Thrasos Therapeutics. H.C.D. reports consulting fees from Glaxo-SmithKline. D.C.M. reports consulting fees from Abbott Vascular MitraClip and Medtronic, and grant support from the PARTNER trial. L.A.V. reports consulting fees from Medtronic. All other authors have nothing to disclose with regard to commercial support.

Read at the 93rd Annual Meeting of The American Association for Thoracic Surgery, Minneapolis, Minnesota, May 4-8, 2013.

Received for publication Oct 8, 2013; revisions received Jan 17, 2014; accepted for publication Feb 1, 2014; available ahead of print March 18, 2014

Address for reprints: Irina V. Volguina, PhD, Division of Cardiothoracic Surgery, Michael E. DeBakey Department of Surgery, Baylor College of Medicine, One Baylor Plaza, BCM 390, Houston, TX 77584 (E-mail: volguina@bcm.edu). $0022-5223 / \$ 36.00$

Copyright (c) 2014 by The American Association for Thoracic Surgery http://dx.doi.org/10.1016/j.jtcvs.2014.02.021 

Abbreviations and Acronyms
$\mathrm{AR}=$ aortic regurgitation
AVR $=$ aortic valve-replacing
AVS $=$ aortic valve-sparing
MAVRE $=$ major adverse valve-related event
MFS = Marfan syndrome
NSVD $=$ nonstructural valve dysfunction
NYHA $=$ New York Heart Association
SVD $=$ structural valve deterioration

316 patients to allow detection of a 2.3-fold difference between the AVR and AVS groups in the risk of valve-related complications. ${ }^{12}$

The enrolled patients had confirmed MFS, had undergone AVS or AVR aortic root replacement, and were available for follow-up. No limitations regarding age, gender, previous cardiovascular intervention, or surgery acuity were included. The type of surgical repair was dependent on the patient's clinical situation and surgeon and patient preference. Using the 1996 Ghent nosology, ${ }^{13}$ the Marfan Diagnostic Core (Johns Hopkins) confirmed the MFS diagnosis clinically for all patients.

Each participating institution's institutional review board or ethics committee approved the study protocol. Each patient gave written informed consent. The protected health information was coded. The funding agencies outside of Baylor College of Medicine had no role in data interpretation.

\section{Data Collection and Definitions}

The data collection and definitions had been previously described in detail. ${ }^{11}$ The clinical data were collected preoperatively, at discharge, and $6,12,24$, and 36 months postoperatively. Echocardiograms were obtained at the same times if possible or whenever available otherwise and were analyzed by the Imaging Core (Mayo Clinic). When digital images were not available, the echocardiographic reports were substituted. The 1-year follow-up period extended from 274 to 457 postoperative days (12 \pm 3 months). The AVS and AVR groups were formed according to the initial operation performed; the AVS procedures were classified according to the definitions suggested by Miller. ${ }^{14}$

Valve-related morbidity and mortality were initially defined according to the 1996 American Association for Thoracic Surgery and Society of Thoracic Surgeons guidelines. ${ }^{15}$ Valve-related complications included structural valvular deterioration (SVD), nonstructural valve dysfunction (NSVD), valve thrombosis, embolism, and bleeding. The consequences of morbid events were defined as reoperation on the aortic valve, valve-related mortality, sudden unexplained death, cardiac death, death from any cause, and permanent valve-related impairment. The 2008 revision of the American Association for Thoracic Surgery, Society of Thoracic Surgeons, and European Association for Cardio-Thoracic Surgery valve-reporting guidelines ${ }^{16}$ introduced an updated composite indicator to capture all types of valve-related events-major adverse valve-related events (MAVRE)—which we used as a primary endpoint. The MAVRE variable was defined as all-inclusive valve-related morbidity and mortality and the need for permanent pacemaker or defibrillator implantation within 14 days of valve intervention.

The patients were categorized as having SVD or NSVD if they had echocardiographic aortic regurgitation (AR) grade $\geq 2+$ or a decline by $\geq 1$ New York Heart Association (NYHA) functional class caused by impairment of the operated valve, pursuant to the 2008 guidelines. ${ }^{16}$ (This method of categorization violated the guidelines in that $\mathrm{AR}$ grade $1+$ was not considered NSVD; see the justification in the "Discussion" section). Conversion from AVS to AVR surgery or from 1 type of AVR to another during the same operation was considered to indicate NSVD. Bleeding was classified as a valve-related event if it occurred after hospital discharge and caused death, hospitalization, or permanent injury or necessitated transfusion, regardless of whether the patient was taking anticoagulant or antiplatelet drugs. Early postoperative bleeding events, such as mediastinal hemorrhage requiring re-exploration, were recorded separately and were not categorized as valve-related complications. The definitions of non-valve-related cardiac, pulmonary, and renal complications have been described previously. ${ }^{11}$

\section{Patients and Operations}

Of the 375 consecutively screened patients who had a tentative MFS diagnosis, needed aortic root replacement, and agreed to participate in the present study, $316(84 \%)$ met the inclusion criteria and were enrolled at 19 participating centers (Table E1). The 59 excluded patients included 54 who did not meet the Ghent criteria and 5 who had undergone isolated valve replacement instead of root replacement. The types of aortic root 
TABLE 1. Operative details

\begin{tabular}{|c|c|c|c|c|}
\hline Operative variable & Total $(\mathbf{n}=316)$ & $\operatorname{AVR}(\mathbf{n}=77)$ & $\operatorname{AVS}(\mathbf{n}=239)$ & $P$ value \\
\hline \multicolumn{5}{|l|}{ Urgency of surgery } \\
\hline Elective & $288(91)$ & $59(77)$ & $229(96)$ & $<.01$ \\
\hline Urgent & $12(4)$ & $7(9)$ & $5(2)$ & \\
\hline Emergency & $16(5)$ & $11(14)$ & $5(2)$ & \\
\hline \multicolumn{5}{|l|}{ Perfusion technique } \\
\hline Cardiopulmonary bypass alone & $246(78)$ & $55(71)$ & $191(80)$ & .1 \\
\hline Circulatory arrest & $70(22)$ & $22(29)$ & $48(20)$ & .1 \\
\hline HCA without perfusion adjuncts & $25(36)$ & $7(32)$ & $18(38)$ & 1.0 \\
\hline HCA with ACP & $19(27)$ & $6(27)$ & $13(27)$ & \\
\hline HCA with RCP & $23(33)$ & $8(36)$ & $15(31)$ & \\
\hline $\mathrm{HCA}$ with $\mathrm{ACP}+\mathrm{RCP}$ & $3(4)$ & $1(5)$ & $2(4)$ & \\
\hline Cardiopulmonary bypass time (min) & $179(141-256)$ & $152(115-197)$ & $194(148-270)$ & $<.01 *$ \\
\hline Aortic crossclamp time (min) & $145(110-208)$ & $115(79-161)$ & $156(117-221)$ & $<.01 *$ \\
\hline Operative time (min) & $340(266-429)$ & $340(245-405)$ & $340(275-441)$ & $.1^{*}$ \\
\hline \multicolumn{5}{|l|}{ Concomitant procedures } \\
\hline Hemiarch & $52(17)$ & $15(20)$ & $37(16)$ & .4 \\
\hline Full arch (without elephant trunk) & $5(2)$ & 0 & $5(2)$ & .2 \\
\hline Elephant trunk and arch & $9(3)$ & $5(6)$ & $4(2)$ & $.03 \dagger$ \\
\hline Mitral valve replacement & $6(2)$ & $5(6)$ & $1(0.4)$ & $<.01 \dagger$ \\
\hline Mitral valve repair & $35(11)$ & $10(13)$ & $25(10)$ & .5 \\
\hline Coronary artery bypass & $13(4)$ & $4(5)$ & $9(4)$ & $.5 *$ \\
\hline
\end{tabular}

Data presented as n (\%) or median (interquartile range). $A V R$, Aortic valve-replacing; $A V S$, aortic valve-sparing; $H C A$, hypothermic circulatory arrest; $A C P$, antegrade cerebral perfusion; $R C P$, retrograde cerebral perfusion. *Independent samples Mann-Whitney $U$ test. $\dagger$ Fisher's exact test.

replacement procedures and operative details are listed in Table E2 and Table 1, respectively. No female patients were pregnant at surgery. Of the 316 patients, $239(76 \%)$ underwent an AVS procedure.

\section{Follow-up Data}

Complete 30-day and in-hospital outcome data were obtained for all 314 surviving patients. The Imaging Core had discharge echocardiographic images available for 240 patients $(76 \%)$ and echocardiographic reports for $61(19 \%)$, for a total of $301(95 \%)$. Twenty-five $(8 \%)$ of these patients had been treated at study sites that only assessed postprocedural AR echocardiographically during surgery and not at discharge; these patients' intraoperative postprocedural echocardiogram or report was used instead.

At $\geq 1$ year, clinical follow-up data were available for $300(97 \%)$ of the 310 surviving patients; 4 patients ( $1 \%$ ) had been lost to follow-up, $4(1 \%)$ had only echocardiographic follow-up data available, and $2(1 \%)$ had follow-up data from a patient interview. The vital status for patients without clinical follow-up or interview data available was cross-checked with the Social Security Death Index. Clinical follow-up data within the 1-year point was available for 208 patients $(69 \%)$; the remaining $92(31 \%)$ had clinical follow-up data available for $>1$ year.

The results of the imaging studies obtained $\geq 1$ year postoperatively were available for $293(95 \%)$ of 310 surviving patients (271 echocardiograms read by the Imaging Core, 20 echocardiogram reports, and 2 electrocardiogram-gated magnetic resonance images). In 5 of the 271 echocardiograms read by the Imaging Core, technical obstacles precluded assessment of AR severity; therefore, local echocardiographic reports were used. For 122 patients (39\%), the first follow-up echocardiogram or report was obtained beyond the 1-year follow-up window. For analysis purposes, the duration of clinical and echocardiographic follow-up was truncated at 457 days, except for 8 patients with later echocardiograms that showed AR grade $\geq 2+$. In those 8 cases, the actual echocardiographic follow-up period was used in the analyses. No echocardiographic follow-up was available for 17 patients $(5 \%$; 4 patients were lost to follow-up, 10 had no follow-up echocardiograms, and 3 had echocardiograms or reports that could not be retrieved from an outside medical institution).

\section{Statistical Analysis}

Normally distributed continuous data are summarized as the mean \pm standard deviation and compared between groups by using Student $t$ tests. Non-normally distributed continuous data are summarized as the median and interquartile intervals, and the Mann-Whitney $U$ test was used for between-group comparisons. Nominal data are presented as frequencies and percentages, and the chi-square or Fisher exact test was used for between-group comparisons, as appropriate. Differences associated with the operation type were assessed using Kaplan-Meier curves, and log-rank tests were used to analyze the time-to-event for each outcome variable, with statistical significance assessed by the log-rank statistic at the .05 level.

Cox proportional hazards models were used to compare the risks associated with patient characteristics (including demographic, preoperative, and operative variables) for each outcome while adjusting for procedure type. Each predictor variable (Appendix E1) was independently evaluated; only the predictors significant at the .05 level were subsequently entered in a multivariable model adjusting for type of operation.

\section{RESULTS \\ Overall Outcomes}

Early 30-day outcomes. One AVS patient died 1 day postoperatively because of bleeding, and 1 AVR patient died 7 days postoperatively of multiple organ failure, for an early overall mortality rate of $0.6 \%$. The incidence of valve-related complications and MAVRE was $5 \%$ and $7 \%$, respectively (Table 2). Valve-related morbid events included 8 cases of NSVD; 6 occurred intraoperatively and resulted in conversion from initial valve-sparing $(\mathrm{n}=5)$ or homograft root replacement $(\mathrm{n}=1)$ to placement of a mechanical composite valve graft. ${ }^{17}$ One other patient required immediate reoperation to correct coronary artery 
TABLE 2. Thirty-day outcomes after aortic root replacement

\begin{tabular}{|c|c|c|c|c|}
\hline Adverse event & Total $(n=316)$ & $\operatorname{AVR}(\mathbf{n}=77)$ & $\operatorname{AVS}(\mathbf{n}=239)$ & $P$ value \\
\hline Mortality & $2(0.6)$ & $1(1)$ & $1(0.4)$ & $.4^{*}$ \\
\hline \multicolumn{5}{|l|}{ Valve-related events } \\
\hline NSVD & $8(3)$ & $1(1)$ & $7(3)$ & $1.0^{*}$ \\
\hline Embolism & $4(1)$ & $1(1)$ & $3(1)$ & $1.0 *$ \\
\hline Bleeding & $5(2)$ & $2(3)$ & $3(1)$ & $.6 *$ \\
\hline Permanent pacemaker within $14 \mathrm{~d}$ & $5(2)$ & $2(3)$ & $3(1)$ & $.6^{*}$ \\
\hline Valve-related morbidity & $16(5)$ & $4(5)$ & $12(5)$ & $1.0^{*}$ \\
\hline MAVRE & $21(7)$ & $6(8)$ & $15(7)$ & $.6^{*}$ \\
\hline Mediastinal re-exploration & $19(6)$ & $7(9)$ & $12(5)$ & $.3 *$ \\
\hline Cardiac complications & $64(20)$ & $27(35)$ & $37(15)$ & $<.01$ \\
\hline Atrial or ventricular arrhythmia & $44(14)$ & $15(20)$ & $29(12)$ & .1 \\
\hline Pericardial effusion requiring drainage & $10(3)$ & $4(5)$ & $6(3)$ & $.3 *$ \\
\hline Cardiac failure & $8(3)$ & $4(5)$ & $4(2)$ & $.1^{*}$ \\
\hline MAVRE and cardiac complications & $74(24)$ & $27(36)$ & $47(20)$ & .1 \\
\hline Pulmonary complications & $26(8)$ & $12(16)$ & $14(6)$ & .01 \\
\hline Acute renal dysfunction & $2(1)$ & $2(3)$ & 0 & $.1 *$ \\
\hline Total postoperative ventilation support time (h) & $9(5-17)$ & $12(8-24)$ & $8(5-15)$ & $<.01 \dagger$ \\
\hline Total ICU stay (h) & $32(22-53)$ & $46(24-72)$ & $26(22-49)$ & $.02 \dagger$ \\
\hline Length of hospital stay (d) & $7(5-9)$ & $7(6-10)$ & $6(5-9)$ & $.01 \dagger$ \\
\hline
\end{tabular}

kinking after an AVS operation (Florida sleeve procedure). Another patient required repair of a coronary artery pseudoaneurysm 6 days after an AVS procedure. The 4 cases of systemic embolism resulted in 2 reversible ischemic neurologic deficits, 1 transient ischemic attack, and 1 stroke. After discharge, 5 patients sustained valverelated bleeding complications, including 3 cases of cardiac tamponade requiring pericardial drainage, 1 of mediastinal bleeding requiring re-exploration, and 1 of gastrointestinal bleeding from an ulcer. Within 14 days postoperatively, 5 patients required a permanent pacemaker because of heart block. No early cases of SVD, valve thrombosis, or endocarditis occurred.

Twenty-seven bleeding events occurred before discharge and were not classified as valve-related complications. Eighteen necessitated mediastinal re-exploration, including 3 at the aortic root site (annular suture line or coronary anastomoses) and 3 at a left atriotomy site or distal aortic anastomosis. Of the 9 patients not requiring re-exploration, 4 had cardiac tamponade (drained in 3, treated conservatively in 1). Other bleeding sites included the left groin, sternum, chest tube tract, lower extremity, and an unidentifiable site.

Pericardial effusion requiring drainage occurred in 10 patients (bloody effusion in 8). One AVR patient experienced a myocardial infarction. Overall, both cardiac $(P<.01)$ and pulmonary $(P=.01)$ complications were more common in the AVR group (Table 2).

One-year outcomes. Six deaths occurred during the first year. The causes of death after 30 days included 1 drowning in the AVS group and 1 case of sepsis complicated by intracranial hemorrhage in the AVR group. In 2 AVS patients, the exact cause of death was unknown but was considered valve-related in accordance with the 2008 guidelines. ${ }^{16}$ At 1 year, the overall survival and freedom from MAVRE was $98 \%$ and $86 \%$, respectively (Table 3). Eight patients $(3 \%)$ were in NYHA class III-IV, and 16 $(6 \%)$ had AR grade $\geq 2+$ (Table E3).

The complications after 30 days included NSVD or SVD (AR $\geq 2+$ ) detected echocardiographically in 16 patients. Echocardiography could not easily distinguish between these modes of valve failure; thus, they were combined into a single NSVD/SVD outcome. The first echocardiographic examination available for 8 of these patients was performed beyond the 1-year threshold. The preoperative aortic valve morphology had been normal in all 16 patients. These patients were more likely than the other AVS patients to have had preoperative AR $\geq 2+(P=.03)$, undergone AVS with the David I technique $(P=.054)$, and had intraoperative, postprocedural, mild AR $(P<.01)$. Bleeding events occurred in 3 patients, including bloody pleural effusion requiring thoracentesis (day 33), gastrointestinal bleeding requiring surgical intervention (day 199), and bloody pericardial effusion (day 128) treated with transfusion and a change in the anticoagulant regimen. Two patients experienced embolic events: 1 transient ischemic attack (day 41) and 1 stroke (day 248). One patient developed endocarditis (day 248). One AVS patient required surgical reintervention on the aortic valve and root for graft infection (day 219). No patient developed valve thrombosis beyond 30 days. 
TABLE 3. One-year operative outcomes after aortic root replacement

\begin{tabular}{|c|c|c|c|c|}
\hline Adverse event & Total $(\mathbf{n}=316)$ & $\operatorname{AVR}(\mathbf{n}=77)$ & $\operatorname{AVS}(\mathbf{n}=239)$ & $P$ valu \\
\hline \multicolumn{5}{|l|}{ Survival and freedom from valve-related events } \\
\hline Overall survival & 98 (96-99), 6/316 & 97 (91-100), 2/77 & 98 (96-100), 4/239 & .6 \\
\hline \multicolumn{5}{|l|}{ Freedom from valve-related events } \\
\hline Valve-related death & 99 (97-100), 3/316 & $99(93-100), 1 / 77$ & 99 (97-100), 2/239 & .7 \\
\hline NSVD/SVD & 92 (89-95), 24/290 & $99(92-100), 1 / 71$ & 90 (85-93), 23/219 & .04 \\
\hline Embolism & 98 (96-99), 6/312 & 97 (91-100), 2/75 & 98 (96-100), 4/237 & .6 \\
\hline Bleeding & 97 (95-99), 8/312 & $93(85-98), 5 / 75$ & 98 (96-100), 3/237 & .01 \\
\hline Endocarditis & $100(98-100), 1 / 316$ & $99(93-100), 1 / 75$ & $100(98-100), 0 / 237$ & .07 \\
\hline Reintervention & $99(98-100), 1 / 316$ & $100(95-100), 0 / 75$ & $100(98-100), 1 / 237$ & .6 \\
\hline Valve-related morbidity & 89 (85-92), 35/312 & $91(82-96), 7 / 77$ & 88 (83-92), 28/235 & .6 \\
\hline MAVRE & $86(81-90), 43 / 295$ & $89(80-95), 8 / 73$ & 85 (79-89), 35/222 & .5 \\
\hline MAVRE and cardiac complications & 68 (63-74), 95/300 & $60(48-71), 30 / 75$ & $71(65-77), 65 / 225$ & .04 \\
\hline \multicolumn{5}{|l|}{ Other complications } \\
\hline Cardiac complications & $72(23)$ & $29(37)$ & $43(18)$ & $<.01$ \\
\hline Atrial or ventricular arrhythmia requiring treatment & $51(16)$ & $17(22)$ & $34(14)$ & .1 \\
\hline Pericardial effusion requiring drainage & $10(3)$ & $4(5)$ & $6(3)$ & .3 \\
\hline Cardiac failure & $10(3)$ & $5(6)$ & $5(2)$ & .07 \\
\hline Pulmonary complications & $30(9)$ & $13(17)$ & $17(7)$ & .01 \\
\hline Acute renal dysfunction & $2(1)$ & $2(3)$ & 0 & .1 \\
\hline
\end{tabular}

Time-to-event estimates for survival and freedom from valve-related events were obtained using Kaplan-Mayer analysis and are presented as percentages (95\% confidence intervals), and number of events/number of observations at the beginning of the interval; "other complications" are reported as n (\%). In 8 of 24 patients, NSVD/SVD due to $\mathrm{AR} \geq 2+$ was detected by echocardiography beyond the 1-year threshold because earlier echocardiograms for these patients were not available. These time-to-event outcomes were compared using the log-rank statistic. No cases of valve thrombosis had developed by 1 year of follow-up. AVR, Aortic valve-replacing; AVS, aortic valve-sparing; $N S V D$, nonstructural dysfunction; $S V D$, structural valve deterioration; MAVRE, major adverse valve-related events.

Cardiac and pulmonary complications were both less common after the initial 30 days (Table 3 ). Ten patients had cardiac complications (days 32 to 419): 5 had atrial or ventricular arrhythmias, 2 had heart block, 2 had congestive heart failure, and 1 had myocarditis. Five pulmonary complications (which developed from days 33 to 189) included 3 pleural effusions requiring drainage and 2 cases of pneumonia.

\section{Comparison of AVR and AVS Groups}

The AVR patients were generally older and sicker than the AVS patients. The AVR group had more patients in NYHA class III-IV and with more severe AR, larger aortic sizes, and a greater prevalence of ascending aortic dissection, cardiomyopathy, and renal failure. Previous cardiovascular operations (Table E1) and urgent or emergency operations (Table 1) were more frequent in the AVR group. The AVR group needed more concomitant elephant trunk arch grafting or mitral valve replacement than the AVS group (Table 1). In contrast, as expected, the aortic crossclamp, cardiopulmonary bypass, and total operative times were longer in the AVS group.

Early mortality did not significantly differ between the 2 groups $(P=.4)$. The rates of early valve-related and cardiac complications, MAVRE, and combined MAVRE and cardiac complications were similar; however, pulmonary problems were more prevalent in the AVR group, which also had a longer mean ventilator support time. The intensive care unit stay and overall hospital stay were both longer for the AVR patients (Table 2).
The Kaplan-Meier analysis of the 1-year outcomes reflected the between-group differences (Table 3, Figures 1 and 2). Although the major endpoints-including overall survival $(P=.6)$, freedom from MAVRE $(P=.6)$, and valve-related morbidity $(P=.7)$-were similar between the groups, freedom from combined NSVD/SVD was greater in the AVR group (99\%) than in the AVS group $(90 \% ; P=.04)$. AR of at least moderate severity $(\geq 2+)$ was present in all 16 cases of combined NSVD/SVD that developed after 30 days in the AVS group. In contrast, only 1 patient had AR $\geq 2+$ in the AVR group. The freedom from bleeding rate was $93 \%$ in the AVR group versus $99 \%$ in the AVS group $(P=.01)$. The AVR patients had more combined MAVRE and cardiac complications $(57 \%$ vs $70 \%, P=.006)$ than the AVS patients. The AVR group also had more cardiac and pulmonary complications. Overall, 7 patients were in NYHA class III and 1 was in class IV. No significant difference was present between the 2 groups $(P=.5$; Table E3).

Cox regression analysis did not identify procedure type as a risk factor for any of the 1-year adverse endpoints. Of the covariates tested for inclusion in the Cox regression model (Appendices E1 and E2), preoperative $\mathrm{AR} \geq 2+$ was significantly associated with valve-related complications $(P=.04)$, and intraoperative postprocedural AR was significantly associated with MAVRE $(P=.03)$, valve-related complications $(P=.02)$, and combined NSVD/SVD $(P<.01)$. Preoperative mitral regurgitation $\geq 2+$ was significantly associated with combined MAVRE 

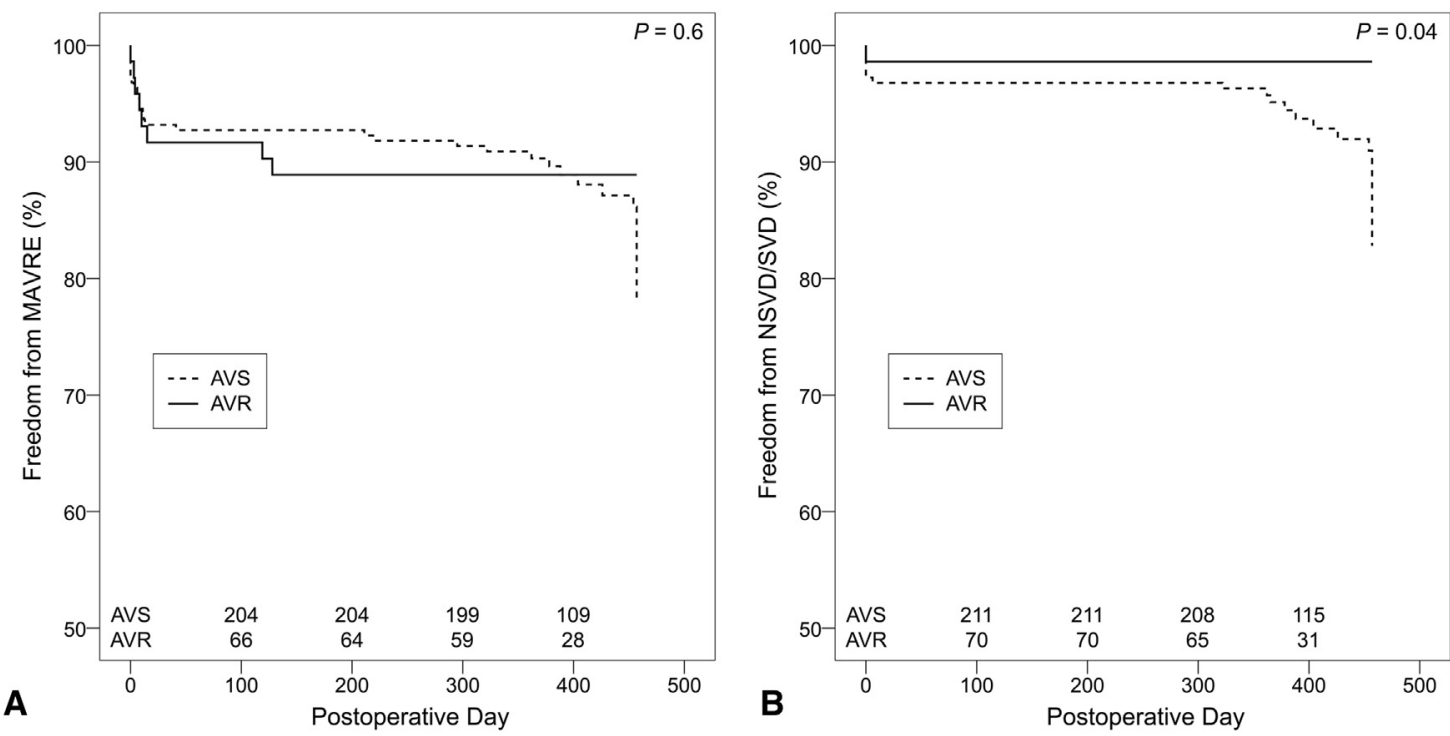

FIGURE 1. Kaplan-Meier analysis of 1-year valve-related events comparing patients who underwent aortic valve-sparing $(A V S)$ and aortic valve-replacing $(A V R)$ root replacement. The $P$ value was obtained by computing the log-rank statistic. A, Freedom from major adverse valve-related events $(M A V R E)$. $\mathrm{B}$, Freedom from nonstructural valve dysfunction/structural valve deterioration (NSVD/SVD).

and cardiac complications $(P=.0049)$. Preoperative mitral regurgitation $\geq 2+$ was also associated with a greater risk of MAVRE $(P=.01)$, and preoperative tricuspid valve regurgitation $\geq 2+$ was associated with a greater risk of bleeding $(P=.04)$. However, the $95 \%$ confidence intervals for the last 2 associations were wide because of the low number of events during the first postoperative year.

\section{DISCUSSION}

The present study is the first prospective investigation to compare the outcomes in patients with MFS concurrently undergoing aortic root replacement using either the AVR or AVS technique. The multicenter design enabled us to determine whether the results would be "generalizable" around the world; it also allowed enough patients to be enrolled within 5 years to potentially avoid the confounding effects of changes in surgical technique. Although the idea was appealing, it would have been unrealistic to attempt to conduct this trial in a randomized fashion; we decided it was in the patients' interest to allow the surgeons to perform whichever procedure they believed was best for each patient in light of that patient's particular clinical circumstances.

Since this study began in 2005, newer techniques for preserving the aortic valve have been developed. Transcatheter aortic valve replacement has been gaining popularity for elderly, very sick patients with aortic stenosis ${ }^{18}$ and has been proposed as a potential "salvage" procedure if the preserved native aortic valve fails. Treasure, Pepper, and Golesworthy and their colleagues from London ${ }^{19}$ have developed a customized, computerdesigned external support mesh prosthesis that can be implanted without cardiopulmonary bypass; they have argued that this device can be used to prevent future aortic root expansion when the patient has not yet reached the conventional thresholds for surgical root replacement. It cannot be used, however, if the patient has AR or if the annulus is markedly dilated.

The present 1-year analysis has confirmed our previous findings ${ }^{11}$ in a larger number of patients. The AVR group was older, had more comorbidities, and more often required emergency or urgent operations. The unadjusted log-rank comparisons of valve-related complications showed a greater prevalence of combined NSVD/SVD in the AVS group. However, bleeding events, non-valve-related cardiac adverse events, and pulmonary complications were more common in the AVR group. The composite MAVRE endpoint did not differ between the AVS and AVR groups, apparently because the differences in individual valve-related complications offset each other in the composite MAVRE variable. Although the Cox regression analysis showed that procedure type had no important influence on any endpoint, the greater prevalence of NSVD/SVD in the AVS group 1 year postoperatively should serve as an alert-much longer follow-up is necessary to reveal the true durability of the AVS approach in patients with MFS. This observation reinforces the conclusion of the recent meta-analysis by Benedetto and colleagues, ${ }^{10}$ who examined 11 retrospective studies that compared valve-related composite outcomes (ie, combined reintervention, thromboembolic event, and endocarditis) and individual complications after either AVS or AVR root replacement in patients with MFS. They found no difference in the composite outcome; however, the AVS 

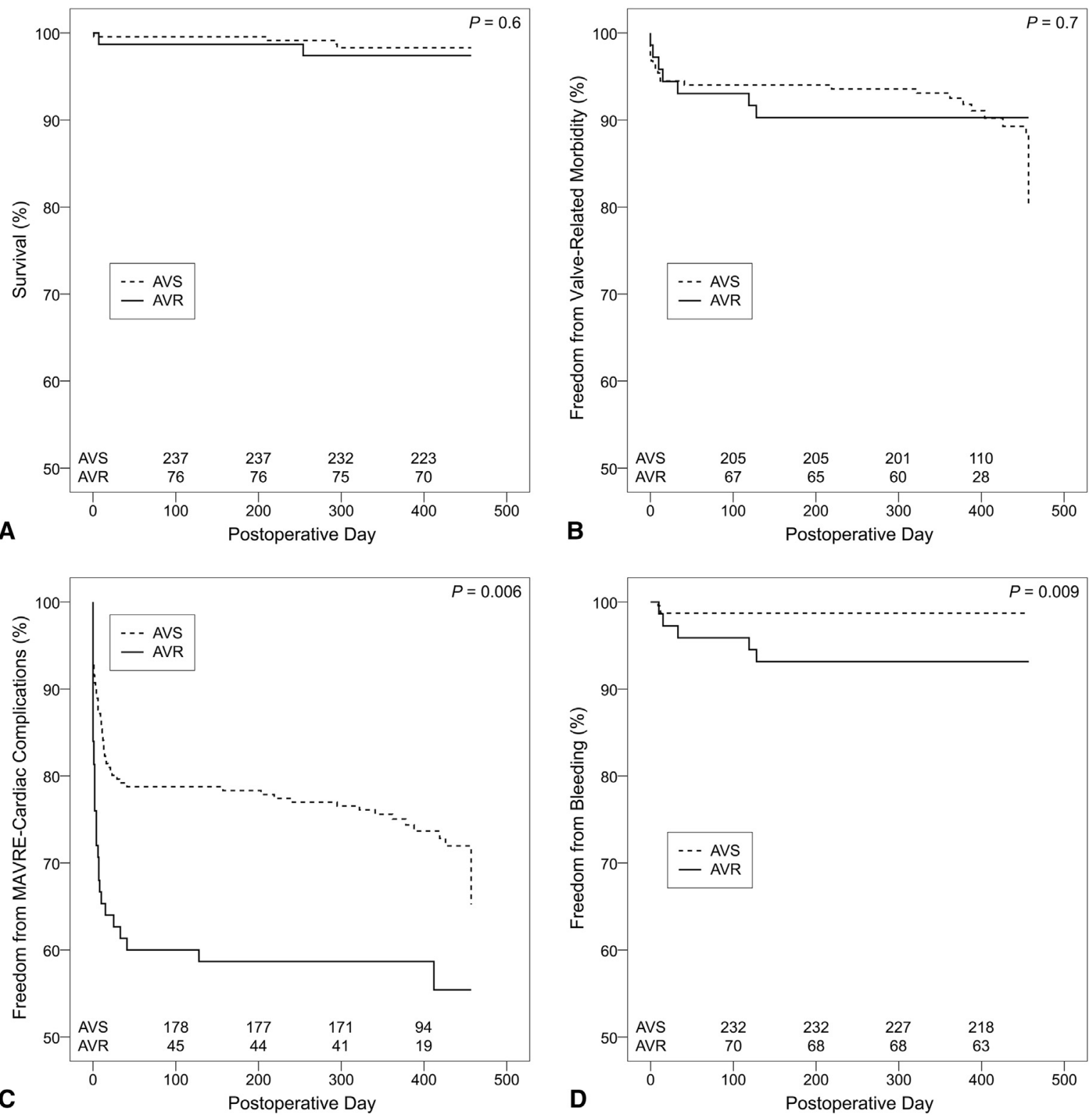

FIGURE 2. Kaplan-Meier analysis of 1-year overall survival and freedom from valve-related events comparing patients who underwent aortic valve-sparing $(A V S)$ and aortic valve-replacing $(A V R)$ root replacement. The $P$ value was obtained by computing the log-rank statistic. A, Overall survival. B, Freedom from valve-related complications. C, Freedom from combined major adverse valve-related events (MAVRE) and cardiac complications. D, Freedom from bleeding.

patients more frequently required surgical reintervention, and the AVR patients had a greater incidence of thromboembolic complications (these 2 individual complications cancelled each other's effects when combined in the composite outcome variable). ${ }^{10}$ The greater 1-year prevalence of NSVD/SVD in our study and the greater reintervention rate reported by Benedetto and colleagues ${ }^{10}$ question the durability of the preserved native aortic valve in patients with MFS. Future investigations that include more patients followed up for long periods are clearly necessary; such studies will also determine the mortality risk associated with reoperation after AVS procedures if the valve fails.

Finally, the 2008 American Association for Thoracic Surgery, Society of Thoracic Surgeons, and European Association for Cardio-Thoracic Surgery valve-reporting guidelines ${ }^{16}$ have stipulated that residual or recurrent mitral or tricuspid regurgitation must be more than mild to qualify as NSVD; however, no similar $\geq 2+$ threshold has been stated for AR after aortic valve repair or AVS aortic root replacement. Because mild (1+) AR is common after AVS (occurring in $25 \%$ of AVS patients in the present 
study), classifying it as NSVD would have caused us to overestimate the incidence of NSVD, and it would not represent a clinically important complication. We suggest that the next iteration of the valve-reporting guidelines be modified according to these findings. The Stanford group recently reported that mild $(1+)$ residual AR was present in fully $43 \%$ of their patients 1 year after David reimplantation AVS. However, it remained stable in $85 \%$ to a median of 57 months, had progressed to $2+$ in only $12 \%$ at a median of 28 months and remained stable thereafter, and had degenerated to $4+$ in only 1 patient. $^{20}$ Hence, our present finding of a greater incidence of NSVD/SVD in the AVS group probably did not portend premature valve failure or the need for reoperation in the medium term, and it certainly did not represent failure of the fundamental valve-sparing concept in patients with MFS.

\section{Study Limitations}

The limitations inherent in the present prospective registry design included the impossibility of standardizing surgical techniques and the possibility of important baseline differences between patient groups. Additional limitations of the study included its nonrandomized design, short follow-up period ( 1 year), and the lack of imaging information for $7 \%$ of the patients at $\geq 1$ year. Another challenge was accurately interpreting the echocardiograms: various echocardiographic techniques were used, and the quality of the images varied. Also, it was impossible to discern in the AVS group whether the AR should represent SVD or NSVD; thus, they were grouped together. Finally, we had to rely on a 1-year echocardiographic report for 20 patients whose digital images were not obtainable or interpretable. The original study was powered to detect a 2.3-fold increased risk of valve-related complications, assuming 3 years of follow-up. Therefore, the 1-year data analysis provided less power to detect significant differences than the upcoming 3-year analysis because fewer events had occurred at 1 year. Because of the insufficient power and multiple hypothesis testing, the 1-year findings should be interpreted with caution. Nonetheless, the data we have presented provide the best comparison to date of the AVS and AVR approaches for aortic root repair.

\section{CONCLUSIONS}

Despite the added complexity of AVS root replacement, this approach was not associated with greater 30-day mortality or a greater MAVRE rate than AVR root replacement. At 1 year, no differences were found in survival, valve-related morbidity, or MAVRE; however, more bleeding events occurred after AVR and more valve dysfunction (NSVD/SVD) after AVS. Of concern, 7\% of AVS patients developed $\geq 2+$ AR during the follow-up period. This finding, combined with the increasing popularity of AVS root replacement, mandates continued follow-up of this well-defined cohort for 5 to 10 years to evaluate the mid- and long-term durability of AVS versus AVR root replacement in patients with MFS.

The Marfan Foundation and the Data Coordinating Center at Baylor College of Medicine express their gratitude to the domestic and international study institutions whose contributions are described below. The study could not have been conducted without their tireless efforts in patient enrollment and data collection.

Stephen N. Palmer, PhD, ELS, contributed to the editing of the manuscript. Scott A. Weldon, MA, CMI, contributed to figure preparation.

Study institutions

Study Cores: Institution (Core Director)

Data Coordination Center and Surgical Core: Baylor College of Medicine (J. S. Coselli, Study Principal Investigator)

Marfan Diagnostic Core: Johns Hopkins Hospital (H. C. Dietz)

Imaging Core: Mayo Clinic, Rochester (H. M. Connolly)

Genetic Repository: University of Texas Medical School at Houston (D. M. Milewicz)

Participating Study Sites: Institution (Site Principal Investigator, Number of Patients Enrolled)

Argentina: Institute of Cardiology and Cardiovascular Surgery-Favaloro Foundation (R. R. Favaloro, 19 patients)

Canada: University of Ottawa Heart Institute (K-L. Chan, 3 patients)

Germany: Hannover Medical School (A. Haverich, 11 patients); Medical University of Luebeck (H. H. Sievers, 13 patients); University of Leipzig (F. W. Mohr, 21 patients)

The Netherlands: Leiden University Medical Center (M. I. M. Versteegh, 3 patients)

United States: Baylor College of Medicine (J. S. Coselli, 15 patients); Central Maine Heart and Vascular Institute (R. P. Cochran, C. Frumiento, 1 patient); Johns Hopkins Hospital (V. L. Gott, L. A. Vricella, 32 patients); Loyola University Medical Center (J. P. Schwartz, 3 patients); Mayo Clinic, Rochester (T. M. Sundt III, H. V. Schaff, 55 patients); Missouri Baptist Medical Center (N. T. Kouchoukos, 8 patients); Montefiore Medical Center (A. DeAnda, 2 patients); New York Presbyterian-Cornell Hospital (L. N. Girardi, 29 patients); Northwestern University Feinberg School of Medicine (T. G. Gleason, C. Malaisrie, 8 patients); Stanford University (D. C. Miller, 49 patients); University of Pennsylvania (J. E. Bavaria, 28 patients); University of Pittsburgh (T. G. Gleason, 2 patients); Washington University (M. R. Moon, 14 patients).

\section{References}

1. Judge DP, Dietz HC. Marfan's syndrome. Lancet. 2005;366:1965-76.

2. Finkbohner R, Johnston D, Crawford ES, Coselli J, Milewicz DM. Marfan syndrome: long-term survival and complications after aortic aneurysm repair. Circulation. 1995;91:728-33

3. Roman MJ, Rosen SE, Kramer-Fox R, Devereux RB. Prognostic significance of the pattern of aortic root dilation in the Marfan syndrome. J Am Coll Cardiol. 1993;22:1470-6.

4. Bentall H, De Bono A. A technique for complete replacement of the ascending aorta. Thorax. 1968;23:338-9.

5. Yacoub M, Fagan A, Stassano P, Radley-Smith R. Results of valve conserving operations for aortic regurgitation [abstract]. Circulation. 1983;68(Suppl III):321. 
6. David TE, Feindel CM. An aortic valve-sparing operation for patients with aortic incompetence and aneurysm of the ascending aorta. J Thorac Cardiovasc Surg. 1992;103:617-21; discussion 22.

7. Murdoch JL, Walker BA, Halpern BL, Kuzma JW, McKusick VA. Life expectancy and causes of death in the Marfan syndrome. N Engl J Med. 1972;286:804-8.

8. Pepper J, Golesworthy T, Utley M, Chan J, Ganeshalingam S, Lamperth M, et al. Manufacturing and placing a bespoke support for the Marfan aortic root: description of the method and technical results and status at one year for the first ten patients. Interact Cardiovasc Thorac Surg. 2010;10:360-5.

9. Birks EJ, Webb C, Child A, Radley-Smith R, Yacoub MH. Early and long-term results of a valve-sparing operation for Marfan syndrome. Circulation. 1999;100: II29-35.

10. Benedetto U, Melina G, Takkenberg JJ, Roscitano A, Angeloni E, Sinatra R. Surgical management of aortic root disease in Marfan syndrome: a systematic review and meta-analysis. Heart. 2011;97:955-8.

11. Volguina IV, Miller DC, LeMaire SA, Palmero LC, Wang XL, Connolly HM, et al. Valve-sparing and valve-replacing techniques for aortic root replacement in patients with Marfan syndrome: analysis of early outcome. J Thorac Cardiovasc Surg. 2009; 137:1124-32.

12. Hintze JL. PASS 2005, Power Analysis and Sample Size User's Guide. Available at: www.ncss.com. 2005. Accessed November 18, 2005.

13. De Paepe A, Devereux RB, Dietz HC, Hennekam RC, Pyeritz RE. Revised diagnostic criteria for the Marfan syndrome. Am J Med Genet. 1996;62:417-26.

14. Miller DC. Valve-sparing aortic root replacement in patients with the Marfan syndrome. J Thorac Cardiovasc Surg. 2003;125:773-8.

15. Edmunds LH Jr, Clark RE, Cohn LH, Grunkemeier GL, Miller DC, Weisel RD. Guidelines for reporting morbidity and mortality after cardiac valvular operations. Ad Hoc Liaison Committee for Standardizing Definitions of Prosthetic Heart Valve Morbidity of the American Association for Thoracic Surgery and The Society of Thoracic Surgeons. J Thorac Cardiovasc Surg. 1996;112:708-11.

16. Akins CW, Miller DC, Turina MI, Kouchoukos NT, Blackstone EH, Grunkemeier GL, et al. Guidelines for reporting mortality and morbidity after cardiac valve interventions. J Thorac Cardiovasc Surg. 2008;135:732-8.

17. Volguina IV, LeMaire SA, Palmero LC, Miller DC, Coselli JS. Intraoperative conversion after surgical failure: an overlooked complication of aortic root replacement in Marfan patients? Tex Heart Inst J. 2011;38:684-6.

18. Fassa AA, Himbert D, Vahanian A. Transcatheter aortic valve replacement: current application and future directions. Curr Cardiol Rep. 2013;15:353.

19. Treasure T, Takkenberg JJ, Golesworthy T, Rega F, Petrou M, Rosendahl U, et al. Personalised external aortic root support (PEARS) in Marfan syndrome: analysis of 1-9 year outcomes by intention-to-treat in a cohort of the first 30 consecutive patients to receive a novel tissue and valve-conserving procedure, compared with the published results of aortic root replacement. Heart. 2014. Epub ahead of print.

20. Stephens EH, Liang DH, Kvitting JP, Kari FA, Fischbein MP, Mitchell RS, et al. Incidence and progression of mild aortic regurgitation after Tirone David reimplantation valve-sparing aortic root replacement. J Thorac Cardiovasc Surg. 2014; 147:169-78.e3.

\section{Discussion}

Dr Gosta Pettersson (Cleveland, Ohio). I represent myself and Dr Stewart, who was the original discussant on this report. I congratulate you for a nice presentation. I congratulate the group for having put together this registry.

The inclusiveness is really the strength of the study, it represents a real world experience. I am, however, in doubt about the ability of this study to distinguish between the AVR and AVS procedures. Nevertheless, this is a remarkable effort to provide better data on how we should treat these patients, because there are still many open questions.

There are 19 centers involved in this registry, but a few centers have provided a larger number of patients. Is there anything to learn about the learning curve of the AVS procedure from this?

Dr Coselli. Yes, 2 things. One, if you consider the 30-day data, there were basically no deaths, no strokes, et cetera. The data from
30 days were excellent for the groups from this collection of institutions. So, consequently, there really was not much in the way of an impact from a learning curve.

When we considered mortality and valve-related events and the influence of the institution, we did not find that it was statistically significant. However, the problem is that with 19 institutions and so many events, it defies a legitimate statistical evaluation.

Dr Pettersson. The age range was from 4 to 70 years, and most recently, the percentage of valve-sparing operations approached $100 \%$. Have you identified any limitations, any contraindications to valve-sparing? Also, what about age? The 4-year-old did not make it, and you said it was nonvalve-related, but still that is an interesting question.

Dr Coselli. I do not recall the exact numbers in the very low end of the pediatric age group, but clearly the 4-year-old patient was a bit of an outlier. However, when we considered age as a variable for valve outcome and survival, it was not a statistically significant factor.

Dr Pettersson. AVS was performed using a number of different techniques. Did that have any effect on residual AR?

Dr Coselli. No, that did not arise. Again, it had to do with the total number of events and the wide number of small variations in technique. So, no, this particular evaluation could not specifically answer that question.

Dr Pettersson. There were a larger number of bleeding events, and you separated them into valve-related and nonvalve-related. A valve-sparing procedure is a significantly longer operation than just replacing the aortic valve-did that not affect bleeding?

Dr Coselli. That is very interesting. There was increased complexity with AVS compared with a standard Bentall operation, removing the patients who had undergone concomitant arch operations, mitral valve repair, et cetera. Thus, although the cardiopulmonary bypass times and crossclamp times were longer, that did not influence the early results or, ultimately, the long-term results.

Dr Pettersson. My final question relates to the conversions. At which stage during the operation did the surgeons decide to abandon trying to save the valve? Conversion after 2.5 hours of crossclamp time is of great concern.

Dr Coselli. We described this group of 6 patients in our 2011 publication. Surgeons abandoned saving the valve if post-procedural excessive aortic regurgitation could not be corrected. While the crossclamp duration before conversion could not be obtained, the total crossclamp time exceeded 3 hours for 5 of the 6 patients. Except for one patient who developed early cardiac tamponade and severe mitral valve regurgitation, there were no short-term or follow-up complications in this group.

Dr Pettersson. Thank you, and I also thank the Association for the privilege to discuss this report.

Dr Marc R. Moon (St Louis, Mo). It is remarkable that operative mortality only occurred in 2 patients with this very complex procedure and complex disease. One of the problems with developing a new innovative technique is that sometimes it is not reproducible. However, Drs David and Yacoub hit the nail on the head. They were able to develop an incredibly complex procedure that is reproducible and safe. 
Dr Coselli. Agreed.

Dr Hitoshi Ogino (Tokyo, Japan). Thank you very much for an interesting study and presentation.

My questions are very simple. Unfortunately, some of the patients developed a stroke during the operation or at the long-term period. What was the cause of the embolism or stroke? What do you think about that?

Dr Coselli. That I do not know in detail. There were 4 cases of early and 2 cases of late embolism that will be described in the upcoming publication.

Dr Ogino. Another question. Some patients developed AR at the long-term period. What is the cause of the AR? Have you analyzed it or did you study it?

Dr Coselli. We are still analyzing that. Again, the imaging core is with Heidi Connolly at Mayo Clinic, and the numbers were still small enough for analysis. However, it was basically leaflet deterioration over time. We know that annular dilatation was not an issue; thus, it was almost always leaflet deterioration.

But what we are going to have to eventually go back and study and determine, and I think this is probably more the core of your question, is whether any of those valve leaflets were prolapsing below the annulus when the patient left the operating room. We are still in the process of evaluating those sorts of factors, but do not have the information for this particular presentation.

Dr Ogino. Thank you very much.
Dr Marc R. Moon (St Louis, Mo). What is the planned long-term follow-up for these patients, and is the study closed now to accrual?

Dr Coselli. Yes. Accrual of the study has been completed. We believe it is reasonably powered. It was initially set up as, in effect, a short-term 3-year follow-up study.

If we can acquire the funding to continue to monitor these patients and pull the data together at the core sites, we will try to continue it for at least 10 years, although it would be ideal to continue for even longer.

This was a unique group of patients because they were all fully vetted for Marfan syndrome through a single, highly qualified genetic program, and all the analysis of the imaging was performed by a single renowned individual.

Thus, the follow-up has been very, very good and the quality of the data excellent. We will just have to see how this holds up over time.

Dr Leonard N. Girardi (New York, NY). You saw over time that a move away from AVR occurred, and almost everybody was undergoing AVS. Did you see a similar move away from remodeling toward reimplantation?

Dr Coselli. Yes. Only 1 remodeling was performed in the whole series, and this patient underwent intraoperative conversion. Almost all these institutions had adopted the inclusion technique and had moved away from the Yacoub technique very, very early on, for all the reasons that we accept. 


\section{APPENDIX E1. VARIABLES TESTED FOR INCLUSION IN REGRESSION MODEL}

1. Type of surgery (AVR vs AVS)

2. Study site

3. Age at surgery

4. Gender

5. Race

6. Smoking status

7. Preoperative New York Heart Association class

8. Preoperative composite aortic regurgitation severity

9. Preoperative composite mitral regurgitation severity

10. Preoperative composite tricuspid regurgitation severity

11. Preoperative dissection

12. Preoperative dissection acuity

13. Preoperative aortic valve disease

14. History of mechanical composite valve graft surgery

15. History of aortic valve resuspension

16. History of homograft aortic root replacement

17. History of mitral valve replacement

18. History of mitral valve repair

19. Hypertension

20. Coronary artery disease

21. Heart failure

22. Cardiac arrest

23. Cardiac arrhythmia

24. Myocardial infarction

25. Endocarditis

26. Dialysis

27. Diabetes

28. Blood urea nitrogen/creatinine ratio

29. Operating surgeon

30. Crossclamp time

31. Cardiopulmonary bypass time

32. Concomitant surgical procedure

\section{APPENDIX E2. KAPLAN-MEIER AND COX REGRESSION ANALYSES \\ Kaplan-Meier Analysis}

Kaplan-Meier curve analysis suggested that the AVR patients were at greater risk of combined MAVRE and cardiac complications $(P=.006)$ and bleeding $(P=.01)$ than were the AVS patients. The AVS patients appeared to have a greater risk of NSVD/SVD $(P=.04)$. The type of surgery was not significantly associated with MAVRE $(P=.6)$, overall mortality $(P=.6)$, valve-related mortality $(P=.7)$, valve-related complications $(P=.7)$, embolism $(P=.3)$, reintervention $(P=.6)$, or endocarditis $(P=.1)$.

\section{Cox Regression Analysis}

- MAVRE

The risk of MAVRE among patients with mitral regurgitation (MR) grade $\geq 2+$ was about 2.6 times greater than among patients with none/trivial/grade $1+$ MR after adjustment for surgery type and postprocedural intraoperative aortic regurgitation (AR; $P=.01)$. The risk of MAVRE among patients with postprocedural intraoperative AR grade $\geq 1+$ was 2.2 times greater than among patients with no postprocedural AR after adjustment for surgery type and MR grade $(P=.03)$. The surgery type itself was not significantly associated with MAVRE (hazard ratio, $0.72 ; 95 \%$ confidence interval $[\mathrm{CI}], 0.3-1.8)$.

- Combined MAVRE and cardiac morbidity

After adjustment for composite MR severity $(P=.005)$, the surgery type was no longer significantly associated with combined MAVRE and cardiac morbidity $(P=.75)$. The risk of experiencing this combined event was about 2.2 times greater for patients with MR grade $\geq 2+$ than for patients with a lower MR grade (none, trivial, or grade $1+$ ).

- Death from all causes

Patients with preoperative MR grade $\geq 2+$ were more likely to die of any cause than were those with a lower MR grade (hazard ratio, 19.7; 95\% CI, 1.6-247.9; $P=.02)$ after adjustment for surgery type. We considered this hazard ratio to be only an indication of a possible relationship, not a reliable estimate, because the $95 \%$ CI was extremely wide. The surgery type was not associated with all-cause mortality $(P=.52)$.

- Valve-related complications

The risk of valve-related complications among patients with preoperative AR grade $\geq 2+$ was 2.2 times $(95 \% \mathrm{CI}, 1.05-4.4 ; P=.04)$ greater than it was among patients with lower preoperative AR, after adjustment for postprocedural intraoperative $A R$ and surgery type. Postprocedural intraoperative AR grade $\geq 1+$ was associated with a 2.4 -fold $(95 \% \mathrm{CI}$, 1.2-4.8) increased risk of valve-related complications after adjustment for surgery type and preoperative AR. The surgery type was not a significant predictor of valve-related complications after adjustment for preoperative AR grade $2+$ and postprocedural intraoperative $\mathrm{AR}(P=.57)$.

- Bleeding

The surgery type $(P=.26)$ was no longer significantly associated with bleeding after adjustment for tricuspid regurgitation severity $(P=.004)$. The risk of bleeding among patients with tricuspid regurgitation severity grades $2+$ or $3+$ was about 12.6 times $(95 \% \mathrm{CI}$, 2.3-70.3) greater than that of patients with none, trivial, or grade $1+$ tricuspid regurgitation severity. 
We considered this hazard ratio to be only an indication of a possible relationship, not a reliable estimate, because the $95 \%$ CI was very wide.

- NSVD/SVD

Patients with postprocedural intraoperative AR were 4.0 times more likely (95\% CI, 1.7-9.1) to have NSVD/SVD than were patients who did not have
AR. The analysis was adjusted for surgery type, which itself was not significantly associated with NSVD/ $\operatorname{SVD}(P=.14)$.

- None of the predictor variables were significantly associated with valve-related death, embolism, reintervention, or endocarditis using Cox proportional hazards modeling. 
TABLE E1. Patient characteristics

\begin{tabular}{|c|c|c|c|c|}
\hline Variable & Total $(\mathbf{n}=316)$ & $\operatorname{AVR}(\mathbf{n}=77)$ & $\operatorname{AVS}(\mathbf{n}=239)$ & $P$ value \\
\hline Age (y) & $35 \pm 13(4-70)$ & $39 \pm 14(8-70)$ & $33 \pm 13(4-65)$ & $<.01$ \\
\hline Male gender & $203(64)$ & $55(71)$ & $148(62)$ & .1 \\
\hline Hypertension & $68(22)$ & $21(27)$ & $47(20)$ & .2 \\
\hline Hypercholesterolemia & $8(3)$ & $2(3)$ & $6(3)$ & $1.0^{*}$ \\
\hline Diabetes & $2(1)$ & 0 & $2(1)$ & $1.0^{*}$ \\
\hline Smoking $\dagger$ (no. of observations) & 315 & 77 & 238 & .7 \\
\hline Current smoker & $24(8)$ & $6(8)$ & $18(8)$ & \\
\hline Former smoker & $59(19)$ & $12(16)$ & $47(20)$ & \\
\hline Recent cerebrovascular accident & 0 & 0 & 0 & NA \\
\hline COPD & $11(4)$ & $2(3)$ & $9(4)$ & $1.0^{*}$ \\
\hline Pneumonia & & & & .1 \\
\hline Current & $1(0.3)$ & $1(1)$ & 0 & \\
\hline Previous & $12(4)$ & $5(7)$ & $7(3)$ & \\
\hline Coronary artery disease & $3(1)$ & $2(3)$ & $1(0.4)$ & $.1^{*}$ \\
\hline MI within $24 \mathrm{~h}$ & $1(0.3)$ & 0 & $1(0.4)$ & $1.0^{*}$ \\
\hline Cardiomyopathy & & & & .01 \\
\hline Current & $7(2)$ & $5(7)$ & $2(1)$ & \\
\hline Previous & $3(1)$ & $1(1)$ & $2(1)$ & \\
\hline MV disease & & & & .7 \\
\hline Current & $192(61)$ & $50(65)$ & $142(59)$ & \\
\hline MV prolapse & $150(47)$ & $34(44)$ & $116(49)$ & \\
\hline MV regurgitation $\geq 2+$ & $9(3)$ & $6(8)$ & $3(1)$ & \\
\hline Combined & $33(10)$ & $10(13)$ & $23(10)$ & \\
\hline Previous & $8(3)$ & $2(3)$ & $6(3)$ & \\
\hline History of endocarditis & $2(1)$ & $1(1)$ & $1(0.4)$ & $.4 *$ \\
\hline Coagulopathy & $6(2)$ & $3(4)$ & $3(1)$ & $.2 *$ \\
\hline NYHA class & & & & .05 \\
\hline I & $216(68)$ & $45(58)$ & $171(72)$ & \\
\hline II & $79(25)$ & $23(30)$ & $56(23)$ & \\
\hline III & $12(4)$ & $4(5)$ & $8(3)$ & \\
\hline IV & $9(3)$ & $5(7)$ & $4(2)$ & \\
\hline NYHA class III-IV & $21(7)$ & $9(12)$ & $12(5)$ & .06 \\
\hline Bicuspid aortic valve & $8(3)$ & $3(4)$ & $5(2)$ & $.4 *$ \\
\hline $\operatorname{LVEF}(\%)$ & $60(55-65 ; 271)$ & $60(55-65 ; 66)$ & $60(55-65 ; 205)$ & $.2 \ddagger$ \\
\hline Sinus rhythm & $309(98)$ & $75(97)$ & $234(98)$ & $.7 *$ \\
\hline AR (no. of observations) & 307 & 76 & 231 & $<.01$ \\
\hline None/trivial (0) & $123(40)$ & $17(22)$ & $106(46)$ & \\
\hline Mild $(1+)$ & $107(35)$ & $21(28)$ & $86(37)$ & \\
\hline Moderate $(2+)$ & $40(13)$ & $13(17)$ & $27(12)$ & \\
\hline Moderate to severe $(3+)$ & $14(5)$ & $10(13)$ & $4(2)$ & \\
\hline Severe $(4+)$ & $23(8)$ & $15(20)$ & $8(4)$ & \\
\hline $\mathrm{AR} \geq 2+$ & $77(25)$ & $38(50)$ & $39(17)$ & $<.01$ \\
\hline \multicolumn{5}{|l|}{ Aortic dimensions (mm) } \\
\hline Annulus & $26(23-28 ; 275)$ & $26(24-29 ; 67)$ & $25(23-27 ; 208)$ & $.01 \ddagger$ \\
\hline Sinuses of Valsalva & $50(47-53 ; 306)$ & $53(49-58 ; 74)$ & $49(46-52 ; 232)$ & $<.01 \ddagger$ \\
\hline Sinotubular junction & $37(33-43 ; 197)$ & $39(34-46 ; 50)$ & $36(32-41 ; 147)$ & .05 \\
\hline Ascending aortic dissection & $30(10)$ & $18(23)$ & $12(5)$ & $<.01$ \\
\hline Dissection type & & & & $<.01$ \\
\hline Acute & $13(4)$ & $7(9)$ & $6(3)$ & \\
\hline Chronic & $17(5)$ & $11(14)$ & $6(3)$ & \\
\hline Aortic rupture & $1(0.3)$ & 0 & $1(0.4)$ & $1.0^{*}$ \\
\hline Previous CV surgery & $29(9)$ & $17(21)$ & $12(5)$ & $<.01$ \\
\hline
\end{tabular}


TABLE E1. Continued

\begin{tabular}{|c|c|c|c|c|}
\hline Variable & Total $(\mathbf{n}=\mathbf{3 1 6})$ & $\operatorname{AVR}(\mathbf{n}=77)$ & $\operatorname{AVS}(\mathbf{n}=239)$ & $P$ value \\
\hline Previous CV operations (n) & & & & $<.01$ \\
\hline 1 & $21(7)$ & $11(14)$ & $10(4)$ & \\
\hline 2 & $6(2)$ & $4(5)$ & $2(1)$ & \\
\hline$\geq 3$ & $2(1)$ & $2(3)$ & 0 & \\
\hline \multicolumn{5}{|l|}{ Previous CV surgery type } \\
\hline AV resuspension & $1(0.3)$ & $1(1)$ & 0 & $.2^{*}$ \\
\hline $\mathrm{AV}$ replacement, $\mathrm{CVG}$ & $2(1)$ & $2(3)$ & 0 & $.6^{*}$ \\
\hline Homograft root & $1(0.3)$ & $1(1)$ & 0 & $.2 *$ \\
\hline MV repair/replacement & $9(3)$ & $3(4)$ & $6(3)$ & $.5^{*}$ \\
\hline \multicolumn{5}{|l|}{ Aortic aneurysm repair } \\
\hline Ascending aorta & $4(1)$ & $3(4)$ & $1(0.4)$ & $.05^{*}$ \\
\hline Descending thoracic aorta & $5(2)$ & $3(4)$ & $2(1)$ & $.1^{*}$ \\
\hline Abdominal aorta & $4(1)$ & $2(3)$ & $2(1)$ & $.3 *$ \\
\hline \multicolumn{5}{|l|}{ Aortic dissection repair } \\
\hline Stanford A & $8(3)$ & $7(9)$ & $1(0.4)$ & $<.01 *$ \\
\hline Stanford B & $6(2)$ & $3(4)$ & $3(1)$ & $.2^{*}$ \\
\hline Other & $6(2)$ & $4(5)$ & $2(1)$ & $.03 *$ \\
\hline Creatinine (mg/dL) & $0.9(0.7-1.0)$ & $0.9(0.8-1.1)$ & $0.8(0.7-1.0)$ & $<.01 \ddagger$ \\
\hline Renal failure & & & & $<.01$ \\
\hline Current & $3(1)$ & $3(4)$ & 0 & \\
\hline Previous & $1(0.3)$ & $1(1)$ & 0 & \\
\hline
\end{tabular}

Data presented as mean \pm standard deviation (range), $\mathrm{n}(\%)$, median (interquartile range), or median (interquartile range; number of observations). AVR, Aortic valve-replacing; $A V S$, aortic valve-sparing; $C O P D$, chronic obstructive pulmonary disease; $M I$, myocardial infarction; $M V$, mitral valve; $N Y H A$, New York Heart Association; $L V E F$, left ventricular ejection fraction; $A R$, aortic regurgitation; $C V$, cardiovascular; $A V$, aortic valve; $C V G$, composite valve graft. *Fisher exact test. †Patients were considered nonsmokers if they had

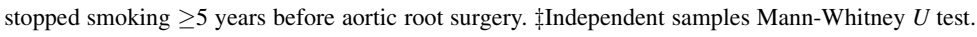

TABLE E2. Types of aortic root replacement $(n=316)$

\begin{tabular}{lc}
\hline \multicolumn{1}{c}{ Root replacement type } & n (\%) \\
\hline Valve-replacing & $77(24)$ \\
Mechanical composite valve graft & 63 \\
Stented bioprosthetic composite valve graft & 8 \\
Stentless porcine root & 4 \\
Homograft root & 2 \\
Valve-sparing & $239(76)$ \\
Reimplantation & 238 \\
David V & 144 \\
Stanford modification & 20 \\
Other modifications & 4 \\
David I & 79 \\
David IV & 14 \\
Florida sleeve & 1 \\
Yacoub remodeling & 1 \\
\hline
\end{tabular}

TABLE E3. New York Heart Association class and aortic regurgitation 1 year after aortic root replacement

\begin{tabular}{lcccc}
\hline \multicolumn{1}{c}{ Adverse event } & Total & AVR & AVS & $\boldsymbol{P}$ value \\
\hline NYHA class & 294 & 71 & 223 & .5 \\
I & $246(78)$ & $60(78)$ & $186(78)$ & \\
II & $40(13)$ & $8(10)$ & $32(13)$ & \\
III & $7(2)$ & $2(3)$ & $5(2)$ & \\
IV & $1(0.3)$ & $1(1)$ & 0 & \\
Aortic regurgitation & 288 & 71 & 217 & .05 \\
None/trivial (0) & $206(71)$ & $60(85)$ & $146(67)$ & \\
Mild (1+) & $66(23)$ & $11(15)$ & $55(25)$ & \\
Moderate (2+) & $12(4)$ & 0 & $12(6)$ & \\
Moderate to severe (3+) & $3(1)$ & 0 & $3(1)$ & \\
Severe (4+) & $1(0.3)$ & 0 & $1(0.5)$ & \\
Aortic regurgitation $\geq 2$ & $16(6)$ & 0 & $16(7)$ & .02 \\
\hline
\end{tabular}

Data presented as $\mathrm{n}(\%) . A V R$, Aortic valve-replacing; $A V S$, aortic valve-sparing; NYHA, New York Heart Association. 